Setting The measurements were carried out in the major regional swimming centers across Hungary.

Patients (or Participants) 304 children (164 male, 140 female), aged 11-13 were involved in the study.

Interventions (or Assessment of Risk Factors) During the two year study period questionnaires about swimming training methods and the existence of shoulder pain were collected, as well as physical examinations were performed.

Main Outcome Measurements The following variables were measured: weekly training hours, the ROM (rotational and elevation) of the shoulders, the ratio of the isometric muscle power, special physical examination tests for impingement syndrome, rotator cuff malfunction, and biceps pathologies.

Results $30 \%$ of the children reported shoulder pain. The following risk factors were common: decreased elevation and internal rotation, increased external rotation and the disbalance of the rotational muscle strength. Children with positive impingement tests had significantly decreased elevation in both shoulders comparing with children with negative physical examination tests $\left(172^{\circ}-179^{\circ}\right)$. There was a significantly decreased elevation of the left infraspinatus $\left(176^{\circ}-179^{\circ}\right)$ and teres minor $\left(177^{\circ}-179^{\circ}\right)$ and the right teres minor $\left(176^{\circ}\right.$ $\left.179^{\circ}\right)$

Conclusions There is evidence that the swimmer's shoulder also exists and shows a relationship with the deviation of the ROM in children who swim actively. It is recommended the optimization of the ROM and the muscle balance of the shoulder muscles. This can only be achieved by performing regular and proper stretching exercises, which therefore can play a huge role to prevent the swimmer's shoulder.

\section{THERE IS NO CONSENSUS ON MOUTHGUARD USE ACROSS SPORTS}

${ }^{1}$ Irfan Ahmed, ${ }^{2}$ Lee James, ${ }^{3}$ Joslin Lynsey Abbey, ${ }^{3}$ Shezad Shahyr, ${ }^{4}$ Needleman lan. ${ }^{1}$ Institute of Sport, Exercise and Health, UCL, London, UK; ${ }^{2}$ Cambridge University Medical school, Cambridge, UK; ${ }^{3}$ UCL medical school, London, UK; ${ }^{4}$ Centre for Oral Health and Performance, UCL Eastman Dental Institute, London, UK., London, UK

\subsection{6/bjsports-2021-IOC.92}

Background Mouthguards are important for injury prevention in athletes. The American Dental Association (ADA) advocates the use of a properly fitted mouthguard in thirty sports to reduce the incidence and severity of sports-related dental injury and oro-facial trauma. Despite this, many athletes cite a lack of formal guidance from individual sport governing bodies as a key reason for not wearing mouthguards.

Objective To audit the current recommendations on mouthguard use, as advised by individual sport governing bodies. The audit standard is the current recommendations from the ADA.

Design An online search was performed of each Olympic, international and national sport governing body. The websites were reviewed for medical guidance, and this was audited to determine whether mouthguards were 'Mandated', 'Recommended', 'Optional', 'Not recommended' or if there was 'No guidance'. Where guidance was available, details on the type and fit of mouthguard recommended and mouthguard care/ maintenance were recorded.

Setting Olympic, international and national sports.
Patients Athletes competing across the thirty ADA 'at-risk' sports.

Interventions (or Assessment of Risk Factors) N/A

Main Outcome Measurements The proportion of 'at risk' sports that have medical guidance on mouthguard use at the level of international governing bodies and national governing bodies. The number of sports with guidance on type, fit and maintenance were also assessed.

Results 10/30 'at risk' sports issue medical guidance on mouthguard use at an international governing body level, of which five mandate usage. 11/30 sports issue guidance at a national governing body level, of which seven mandate usage. 5/30 sports have guidelines on mouthguard type or fit, and only $1 /$ 30 offered guidance on mouthguard care and maintenance.

Conclusions There is a lack of clear guidance for athletes on mouthguard use and care consensus across sports is needed, which could contribute to enhanced protection of athlete health and wellbeing.

\section{IMPACT OF NUTRITIONAL ROUTINE AND TRAINING METHODS USED BY SRI LANKAN NATIONAL TAEKWONDO PLAYERS FOR WEIGHT LOSS PRIOR TO COMPETITION}

Dilumini Kawshila Meegoda, Shalika Harshani Perera, Sameera Perera, Sarmilan Linganathan. Department of Sport Sciences and Physical Education, Faculty of Applied Sciences, Sabaragamuwa University of Sri Lanka, Belihuloya, Sri Lanka

\subsection{6/bjsports-2021-IOC.93}

$(\mathrm{n}=25)$

Objective To determine the weight control strategies used by Sri Lankan national Taekwondo players who were in the SAG (South Asian Games) pool 2020.

Design A population study.

Setting and Participants Sri Lankan national taekwondo pool $(n=25)$. The national taekwondo pool consists of 14 female athletes and 15 male athletes who engage in sparring.

Assessment of Risk Factors Duration of administration was June to August of 2020 in Sri Lanka. Weight loss training methods were identified as the independent variable. Data were collected through questionnaires; mainly weight loss methods and eating attitude questionnaire.

Main Outcome Measurements Physiological and psychological effects of weight loss methods and eating disorders were considered as the dependent variable.

Results Of the 25 participants, $40 \%$ of the athletes reported using a method of rapid weight loss. Five methods were more frequently used, as follows: reduce food consumption $68 \%$, skipping meals 28\%, fasting 32\%, restricting fluids $72 \%$ and using ergogenic aids $12 \%$. The highest weight loss rate before the competition is $6.00 \pm 1.50(\mathrm{~kg})$ in males and $6.00 \pm 1.00$ $(\mathrm{kg})$ in females. Athletes reported to usually lose $\sim 2 \%$ of their body weight. The athletes do not use ergogenic aids and the frequency percentage of physiological and psychological adverse effects of rapid weight loss is very low. Athletes of $48 \%$ of athletes having eating disorders and need for an investigation by a qualified professional. Of them, $60 \%$ are using rapid weight loss method.

Conclusions According to the results, the rapid weight loss training methods, lead to significant undernutrition, with potential dangers for health and performance because of certain deficiencies. 